The verifiability approach in insurance settings

RUNNING HEAD: The verifiability approach in insurance settings

Using the verifiability lie detection approach in an insurance claim setting

\author{
Aldert Vrij ${ }^{1}$ \\ Psychology Department, University of Portsmouth \\ Email: aldert.vrij@port.ac.uk
}

Galit Nahari

Department of Criminology, Bar-Ilan University

Email:galit.nahari@biu.ac.il

Rebecca Isitt

Sharon Leal

Psychology Department, University of Portsmouth

\footnotetext{
${ }^{1}$ Correspondence concerning this article should be addressed to Aldert Vrij, University of Portsmouth, Department of Psychology, King Henry Building, King Henry 1 Street, Portsmouth PO1 2DY, Portsmouth, United Kingdom. E-mail: aldert.vrij @port.ac.uk.
} 
The verifiability approach in insurance settings

\begin{abstract}
In this experiment we tested the verifiability approach in an insurance claim setting. Core of the verifiability approach is that truth tellers give more details that can be verified than liars. Fifty undergraduate students took part, who produced true and false insurance claim statements related to theft, loss or damage. These statements were coded in terms of verifiability (the number of details that could be checked by an investigator) and witness factors (friends, police, other officials, CCTV cameras). Truth tellers provided more verifiable details than liars and liars provided more unverifiable details than truth tellers. In addition, truth tellers (vs liars) more frequently informed their friends about the incident or referred to CCTV footage of the incident. The potential and limitations of using the verifiability approach in insurance settings are discussed.
\end{abstract}




\section{Using the verifiability lie detection approach in an insurance claim setting}

For many decades forensic deception research primarily focused on police suspect interviews (Vrij \& Granhag, 2012, 2014). Recently it has been argued that other domains neglected in deception research are equally important, such as lie detection in intelligence interviews (Brandon, 2011). Another important but neglected area is lie detection in financial settings. For example, the Association of British Insurers (ABI, 2009) reported that $20 \%$ of general insurance holders in the UK said that they would consider making an exaggerated or completely made up insurance claim in the future. The ABI further estimated that undetected insurance claims fraud totals $£ 1.3$ billion a year in the UK in 2013 , adding $£ 50$ to the annual costs of individual policy holders (BBC, 2014, http://www.bbc.co.uk/news/business27608316).

Financial settings are different from police interviews and require new research (Leal, Vrij, Warmelink, Vernham, \& Fisher, 2015; Nahari, Leal, Vrij, Warmelink, \& Vernham, 2014). A good example where police interviews and financial interviews differ is in the applicability of the verifiability approach and the present experiment examines the applicability of the verifiability approach in an insurance claims setting.

Nahari and her colleagues introduced the verifiability approach for assessing the veracity of an alibi (Nahari \& Vrij, 2014; Nahari, Vrij, \& Fisher (2014a, b; Nahari, Vrij, Leal et al., 2014). Central to the verifiability approach are two assumptions. First, truth tellers typically include more detail into their accounts than liars (Masip, Sporer, Garrido, \& Herrero, 2005; Vrij, 2008). Observers seem to be aware of this, 
with the richer, more detailed accounts typically being perceived as more believable (Bell \& Loftus, 1989; Johnson, 2006; Johnson, Foley, Suengas, \& Raye, 1988). As a result, liars will be inclined to provide many details in order to make an honest impression on observers, and they reported such a strategy in Nahari, Vrij, and Fisher (2012). Second, liars prefer to avoid mentioning too many details out of fear that investigators can check such details and will discover that they are lying (Masip \& Ces, 2011; Nahari et al., 2012). Those two assumptions put liars in a dilemma. On the one hand, they are motivated to include many details so that they make an honest impression, and, on the other hand, they are motivated to avoid providing details to minimise the chances of being caught. A strategy that compromises between these two conflicting motivations is to provide details that cannot be verified. When attempting to make an honest impression, liars may choose to provide details that are difficult to verify (e.g., 'Several people walked by when I sat there') and may avoid providing details that are easy to verify (e.g., 'I phoned my friend Fred at 10.30 this morning'). If so, liars may report fewer details that can be checked than truth tellers. In alignment with these predictions, in three out of four experiments testing the verifiability approach, it was found that liars provided fewer details that could be verified than truth tellers (Nahari \& Vrij, 2014; Nahari, Vrij, \& Fisher, 2014a, b). A fourth experiment did not find a difference between truth tellers and liars in reporting verifiable details (Nahari, Leal et al., 2014). This experiment differed from the other three experiments in that (mock) insurance claims were examined rather than (mock) criminal activities.

Insurance settings differ in one fundamental aspect from police settings (Nahari, Leal et al., 2014). In criminal investigations the investigator often knows when a crime occurred. Therefore, when a suspect provides an alibi showing that s/he 
was not at the crime scene at the time the crime occurred (e.g., a bank robber suspect demonstrates that s/he was at a birthday party of a friend when the robbery took place), s/he can be ruled out as being the culprit of the crime (e.g., Olson \& Wells, 2004). In insurance claims settings the situation is different because the claimant will tell the investigator at what time the incident (loss, theft or damage) occurred. This allows a liar to choose a truthful event and to embed a lie about the insurance incident into this event. Thus, the claimant can say that $\mathrm{s} / \mathrm{he}$ lost his/her phone at a birthday party that s/he truthfully attended (e.g. "On my way home from the birthday party, I noticed that my phone was not in my bag"). This birthday party can only show that someone is telling the truth about the insurance claim if the interviewee actually relates the birthday party to the incident, by saying that the incident has been witnessed by others present at that party or that the interviewee has mentioned the incident to other people at the party. In other words, whereas in many police investigations demonstrating that someone was not at the crime scene at the time the crime occurred indicates that person's innocence, in an insurance case the most important factor is that the incident has been witnessed or has been discussed with others. In alignment with these observations, Nahari, Leal et al. (2014) found in their mock insurance experiment that truth tellers (vs liars) reported more frequently that someone who could be identified had witnessed the event, whereas no difference emerged between truth tellers and liars in reporting verifiable details about their activities and whereabouts at the time of the alleged incident.

We examined the verifiability approach in insurance settings in the present experiment, and made three important changes compared to Nahari, Leal et al. (2014). In Nahari, Leal et al. (2014) interviewees were not informed by the investigator that s/he may check the detail provided by the examinee, whereas such information was 
The verifiability approach in insurance settings

given to participants in the present experiment. Nahari, Vrij and Fisher (2014b) found that -in a criminal investigations setting- the verifiability detail effect became stronger when participants were informed that their detail may be checked, as it resulted in truth tellers, but not liars, providing more verifiable detail. When truth tellers are aware that investigators examine checkable detail, they may search their memory for such details. In contrast, liars cannot demonstrate that they were somewhere else other than at the crime scene, so this instruction cannot have an effect on them. Perhaps the same principle works in insurance settings. Perhaps truth tellers can add verifiable detail that are related to the incident (e.g., 'If you check the CCTV footage, you will see that someone stole my bike'), whereas liars may be less likely to do that as they realise that the CCTV footage won't demonstrate an incident. Because we instructed participants in the present experiment that the investigator may check for verifiable details, we hypothesized that truth tellers will report more verifiable details than liars (Hypothesis 1).

A second difference between Nahari, Leal et al. (2014) and the present experiment is that we examined in more detail what type of witness factors participants did mention. Nahari, Leal, Vrij et al. (2014) included several types of witness factors (friends, police, other officials, CCTV footage) but did not distinguish between them, whereas we did. For friends we made a further distinction into whether or not the participant reported to have informed their friend(s) about the incident (Nahari, Leal et al. [2014] did not have a 'friends present but not informed' category.) Truth tellers may inform their friends about the incident more frequently than liars. For example, if truth tellers discover that their phone went missing during a night out with friends, they may ask their friends whether they have seen the phone or anything suspicious or whether a friend could call the missing phone. If liars, who only pretend 
The verifiability approach in insurance settings

that their phone went missing, involve friends in their lie, it makes lying more complicated. Since investigators may contact these friends, liars either need to ask their friends to back up their lie and to produce a false statement for them or they need to lie to their friends and also pretend to them that the incident occurred. People do not like lying to close friends (DePaulo, Ansfield, Kirkendol, \& Boden, 2004; DePaulo \& Bell, 1996: DePaulo \& Kashy, 1998). People also believe that they are poor at lying to their friends and that their friends can easily discover that they are lying (Elaad, 2003). Liars may therefore be reluctant to report that they discussed the incident with their friends.

For witnesses other than friends, such as bar tenders and police, the same reasoning as above applies. It makes sense that truth tellers would have informed those officials, and thus can mention them, but liars may be more reluctant to mention them. We also examined whether participants would report the action taken by these officials. Again, truth tellers may be more willing than liars to report this. It seems logical for truth tellers to do, whereas it only further complicates the lie for the liars. We finally examined whether participants would report that CCTV cameras were present at the location where the incident occurred. CCTV footage recording the incident would provide strong evidence that the incident actually occurred, so truth tellers will be keen to report it. Liars may be more reluctant as, once that footage is checked, the lie may fall through. We also examined whether the participant reported that the CCTV footage had been checked. Truth tellers may well have asked the CCTV footage to be checked and could report this. Reporting that the CCTV footage has been checked would further complicate the lie for liars, and we thus expected liars to be reluctant to do this. 
The verifiability approach in insurance settings

In sum, we predicted that truth tellers (versus liars) will report more frequently: (i) that they had informed the friends who were with them about the incident, (ii) that they had informed other officials (police, bar tenders etc.) about the event, (iii) the actions taken by the other officials, (iv) that CCTV cameras were present at the scene of the incident and (v) that they have checked the CCTV footage (Hypothesis 2).

We finally examined participants' experiences and strategies while writing their true or false insurance claim, something Nahari, Leal et al. (2014) did not do. Fabricating verifiable detail is difficult and often an impossible task and we thus expected that truth tellers (vs liars) will report that they were more convincing and provided more verifiable detail, and that liars (vs truth tellers) will report that including verifiable detail was more difficult to do (Hypothesis 3).

We explored via open-ended questions (i) What strategies participants had used to appear convincing, (ii) Which difficulties they experienced when providing verifiable details, (iii) The reasons for adding specifics about time and location in their statements (in case they did so), and (iv) The reasons for adding other people (witnesses) to the statement (in case they did so). Examining such issues has been neglected for a considerable time in deception research in general (DePaulo et al., 2003) and in insurance setting in particular, yet it is important. Obtaining insight into the thought processes of truth tellers and liars may reveal differences between truth tellers and liars which subsequently can be exploited by investigators through specific interview styles (Vrij \& Granhag, 2012). In fact, the verifiability approach was designed because liars in Nahari et al. (2012) indicated that their strategy was to provide details investigators cannot check. Intriguingly, such a strategy was never 
The verifiability approach in insurance settings

mentioned in other publications about liars' verbal strategies. In these studies it was mostly found that truth tellers prefer to 'tell it all' whereas liars prefer to keep their stories simple (Colwell, Hiscock-Anisman, Memon, Woods, \& Michlik, 2006; Hartwig, Granhag, \& Strömwall, 2007; Hartwig, Granhag, Strömwall, \& Doering, 2010; Payne, 2007; Vrij, Mann, Leal, \& Granhag, 2010).

\section{Method}

\section{Participants}

A total of 50 volunteers ( 22 females) took part in the experiment and were recruited through convenience sampling. Their mean age was $M=25.92$ years $(S D=$ 9.07 years).

\section{Procedure}

Participants (acquaintances of the researcher, mostly undergraduate students) were approached individually by the researcher mostly in the University building or student accommodation and asked if they would be willing to participate in a psychological study about deception in insurance claims. Upon obtaining informed consent and basic demographic information (age and gender), participants were asked to read the instructions given to them. In order to allocate participants to the truth or lie condition, each participant was asked: 'Have you had any item of yours lost or stolen in the past three years that was worth between $£ 100$ and $£ 1000$ ?' If answered 'yes' (which was the case in about $40 \%$ of the people who were approached) the participant was allocated to the truth condition, if answered 'no' the participant was allocated to the lie condition. This method resulted in liars being recruited somewhat quicker than truth tellers. We stopped recruiting liars after 25 took part. From that 
moment anyone who wanted to take part but could not be allocated to the truthful condition were told that liars were no longer recruited and were thanked for their willingness to participate.

Truth tellers $(n=25)$ were then asked to imagine that they were submitting a claim about their lost/stolen item to an insurance company. They were asked to type a personal statement to describe their real incident of loss/theft in as much detail as possible. They were told that they needed to convince the insurance investigator that they were telling the truth, and that their item indeed had been lost or stolen. They were further informed that they may be asked further questions to check the verifiability of their statement or to check the occurrence of the facts they had provided in their statement. They were given time to prepare themselves before writing down their statement.

Liars $(n=25)$ were asked to imagine that they were submitting a claim about a lost/stolen item to an insurance company. They were asked to type a personal statement to describe a fabricated incident of loss/theft in as much detail as possible. It was left entirely up to them what type of statement to fabricate. Like the truth tellers, they were told that they needed to convince the insurance investigator that they were telling the truth, and that their item indeed had been lost or stolen. They were further informed that they may be asked further questions to check the verifiability of their statement or to check the occurrence of the facts they had provided in their statement. They were given time to prepare themselves before writing down their statement.

After typing their statements participants completed a questionnaire. In the questionnaire they were given 11-point Likert scales ranging from $0 \%$ (not at all) to 
$100 \%$ (very much so) and asked to indicate (1) their motivation to write a believable statement, (2) whether they thought they were convincing, (3) whether they thought their statement was verifiable, (4) how difficult they found it to report verifiable details, and (5) the extent to which they told the truth in their statement.

Participants were finally asked to answer the following four additional openended questions: (1) Did you use a strategy to appear convincing in your statements?, (2) Please specify the difficulties in providing verifiable details in your statements (if any?), (3) Did you add any specific details about the time and location of the incident?, and (4) Did you mention people that witnessed the incident of the theft?

Participants wrote statements about four types of event: (i) Loss in public location when friends were present, mostly pubs (13 truth tellers and 12 liars), (ii) loss in public location when friends were not present, e.g., library, departure hall (7 truth tellers and 5 liars), (iii) broken into (four truth tellers and four liars), and (iv) assault (one truth teller and four liars). No difference emerged between truth tellers and liars in the type of event they discussed, $\chi^{2}(3, \mathrm{n}=50)=2.17, p h i=.21, p=.53$.

Six liars did not report when the alleged event took place, but all other 19 liars and all 25 truth tellers did. Truth tellers reported that the event took place on average $M=5.40(S D=5.46)$ months ago, whereas liars reported it took place on average $M=$ $8.26(S D=7.42)$ months ago, this difference was not significant, $t(42)=1.48, p=.15$, $d=.44$. All reported truthful events took place between 0 and 22 months ago, whereas all deceptive events took place between 0 and 23 months ago.

\section{Coding the Verifiability of the Statements}


All statements were rated by one coder (blind to the experimental condition) who was asked to mark on the statements all the perceptual details (information about what the participant saw, heard, felt, or smelt during their alleged activities), spatial details (information about locations or the spatial arrangement of people and/or objects), and temporal details (information about when the event happened or an explicit description of a sequence of events) that potentially could be or could not be verified. The coders did not distinguish between these three categories of detail because no hypotheses about these three subcategories were formulated. Specifically, similar to Nahari et al. (2014a, b), verifiable details were activities that were (i) documented and therefore checkable (e.g., phone calls, withdrawing cash from a cash machine), or when the interview said that the activities were (ii) carried out together with (an)other identified person(s), (iii) witnessed by (an)other identified person(s) or (iv) witnessed by CCTV cameras. Unverifiable details were activities such as asking a stranger for directions, or activities carried out on their own without the interviewee mentioning that other identified persons or CCTV cameras have witnessed the incident. A second coder was also asked to mark on a random sample of 16 statements all details and also to categorise them into verifiable and unverifiable detail. The ICC for coders (based on the total number of details provided in the statements) was satisfactory for verifiable detail $(\mathrm{ICC}=.59)$, unverifiable detail $(\mathrm{ICC}=.72)$ and total detail $($ ICC = .92). The ICC for verifiable detail was relatively low but was caused by one statement (ICC was .72 without that statement). In the statement the participant refers to 'several other people', which the second coder mistakenly interpreted as verifiable persons. Since the participant did not report who these people were, they cannot be consulted and, as a consequence, all the details that these other people may have witnessed cannot be coded as verifiable detail (which the second coder did). 
Apart from reporting the number of verifiable and unverifiable detail mentioned by the participant we also calculated the ratio of verifiable detail (verifiable detail/total detail) and how many participants gave more verifiable than unverifiable detail in their statements. Regarding the ratio, the score could range from 0 to 1. A score of .50 means that a statement included the same number of verifiable and unverifiable details. A score above .50 means that the statement included more verifiable than unverifiable details and a score below .50 means that the statement included less verifiable than unverifiable details.

Two coders noted independently from each other the following witness factors in the statement (the agreement rate between the two coders is provided in brackets): (1) mentioning friends who were not informed about the incident (96\% agreement rate; Cohen's Kappa $=.90, p<.001),(2)$ mentioning friends who were informed about the incident (98\%; Cohen's Kappa $=.96, p<.001)$, (3) mentioning that the police has been informed (98\%; Cohen's Kappa $=.95, p<.001)$, (4) mentioning the response by the police $(98 \%$; Cohen's Kappa $=.92, p<.001)$, (5) mentioning that other officials than the police has been informed $(98 \%$; Cohen's Kappa $=.96, p<.001)$ and $(6)$ mentioning their responses $(94 \%$; Cohen's Kappa $=.88, p<.001)$, (7) mentioning that CCTV cameras were present (94\%; Cohen's Kappa $=.83, p<.001)$ and (8) mentioning that CCTV footage has been watched (98\%; Cohen's Kappa $=.92, p<$ .001). The few disagreements between coders were resolved in a discussion between the coders.

\section{Coding the Open-Ended Questions Responses}

One coder read the participant's responses, designed for each question possible answer categories to classify these responses, and classified the responses into these categories. A second coder also classified all the responses in the categories 
designed by the first coder. The percentage agreement scores between the two coders was $73.1 \%$ for 'strategy', $74.2 \%$ for 'difficulty', $80 \%$ for 'time and location' and 84.1\% for 'people'. All these agreement scores are acceptable. The two coders resolved their disagreements through discussions.

\section{Results}

\section{Veracity Manipulation Check and Being Motivated}

As Table 1 shows, truth tellers reported that they overwhelmingly told the truth $(96 \%$ [SD $=12.24]$ of statement was truthful), whereas liars reported that they overwhelmingly lied $(85.20 \%$ [SD $=26.94]$ of statement was deceptive). In addition, truth tellers and liars were equally motivated and both groups reported high motivation scores $(87.20 \%[\mathrm{SD}=13.08]$ and $82.40 \%[\mathrm{SD}=24.03]$ on a $100 \%$ scale $)$.

\section{Questionnaire Hypotheses testing}

As Table 1 shows, truth tellers (vs liars) thought that their statement was more convincing, supporting Hypothesis 3. In Hypothesis 3 it was further predicted that truth tellers would think that their statement was more verifiable and that liars would find it more difficult to present a verifiable report. The findings did not support these predictions. Both truth tellers and liars thought that their statement was generally verifiable $(73.20 \%[S D=29.26]$ and $61.20 \%[S D=29.06]$ on a $100 \%$ scale $)$, with no difference between the two groups. Both truth tellers and liars found it moderately difficult to produce a verifiable statement $(50.40 \%[S D=32.97]$ and $52 \%[S D=$ 28.28 ] on a $100 \%$ scale) with again no difference between the two groups.

Table 1 about here

\section{Verifiability of Statements}


The verifiability approach in insurance settings

Data were analysed with t-tests with Veracity as the only factor for continuous variables or with Chi-square analyses for categorical variables. As Table 2 shows, truth tellers included more verifiable details in their statements than liars (supporting Hypothesis 1), whereas liars included more unverifiable details in their statements than truth tellers. (In terms of total detail [verifiable and unverifiable details combined] truth tellers $(M=22.00, S D=8.84,95 \%$ CI $[18.32,25.69])$ and liars $(M=$ $20.84, S D=9.48,95 \%$ CI $[17.16,24.53])$ did not differ from each other, $t(48)=.448$, $p=.657, d=.13$. $)$ The ratio variable showed that $76 \%(S D=.21)$ of the details in truthful statements were verifiable versus $46 \%(S D=.31)$ of the details in deceptive statements. This difference was significant and provides further support for Hypothesis 1 . Significantly more truth tellers (84\%) than liars (44\%) included more verifiable than unverifiable detail in their statements, which provides additional support to Hypothesis 1.

Table 2 about here

Regarding the witness factors, significant differences emerged for ' $\mathrm{CCTV}$ footage' and 'friends'. Truth tellers (vs liars) were more inclined to discuss the incident with friends they mentioned in their statement, whereas liars (vs truth tellers) were more inclined not to discuss the incident with friends they mentioned in their statement. Truth tellers (vs liars) also reported more that CCTV footage was present at the location where the incident occurred and that they actually checked that CCTV footage. These findings support Hypothesis 2.

We re-tested the 'friend' variable just for those cases in which the participant reported to have been with friends when the incident happened. A total of 13 truth tellers and 12 liars reported a loss in a public location when they were out with 
friends. Ten out of 13 truth tellers (77\%) and only two out of twelve liars (17\%)

discussed the incident with their friends, $\chi^{2}(1, \mathrm{n}=25)=9.08, p=.003$, phi $=.60$. This gives additional support to Hypothesis 2.

No differences between truth tellers and liars emerged regarding informing the police or other officials about the incident and reporting the actions taken by the police and other officials. Such differences were predicted in Hypothesis 2.

Similar to Nahari, Leal et al. (2014) we calculated a 'total witness' factor which was a combination of the 'friends informed', 'police', other officials' and 'CCTV camera' variables. Significantly more truth tellers (88\%) than liars (64\%) included at least one of these witness factors into their account, which also supports Hypothesis 2.

\section{Open-ended Questions}

Participants were asked four open-ended questions. Their answers varied widely and are all reported in Table 3 . In this section we discuss the answers given by at least three liars or at least three truth tellers. Of course, three is an arbitrary number but it represents a good balance between reporting too much or too little information.

\section{Strategies}

As Table 3 shows, more liars $(n=23,92 \%)$ than truth tellers $(n=8,32 \%)$ reported to have used a strategy, $\chi^{2}(1, \mathrm{n}=50)=6.18, p<.001, p h i=.25$. Those who did not use a strategy - mainly truth tellers - justified this by saying that this was not needed as they just told the truth. The 23 liars and 8 truth tellers who did use a strategy, used different strategies, $\chi^{2}(11, n=31)=20.55, p=.038$, phi $=.81$. Liars 
just imagined the situation, or added details but avoiding specifics. Truth tellers added specific details, but also liars reported to have done this.

Table 3 about here

\section{Difficulty in reporting verifiable details}

Table 3 further shows that a similar number of truth tellers $(n=19)$ and liars $(n=22)$ listed difficulties in reporting verifiable details, $\chi^{2}(1, \mathrm{n}=50)=1.22, p=.27$, $p h i=.16$. The difficulties they listed did not differ between truth tellers and liars, $\chi^{2}(8$, $\mathrm{n}=41)=9.56, p=.30, p h i=.48$. For both truth tellers and liars the most frequently reported difficulty was that there were no verifiable details to provide (mentioned by 15 out of 22 liars and 8 out of 19 truth tellers). The second most frequent difficulty mentioned by both truth tellers and liars was a 'vague memory' to provide such details (mentioned by 3 out of 22 liars and 7 out of 19 truth tellers).

\section{Adding specifics about times and locations}

Table 3 shows that more truth tellers $(n=24,96 \%)$ than liars $(n=14,56 \%)$ reported that they had added specifics about times and locations to their statements, $\chi^{2}(1, n=50)=10.97, p=.001, p h i=.47$. Also the reasons why they did so differed, $\chi^{2}(7, n=38)=20.03, p=.006, p h i=.73$, Truth tellers included specifics so that their statement could be checked (12 out of 24 truth tellers) and to make the statement more accurate and clear (4 out of 24 truth tellers). Liars included specifics to make their statement sound more believable (10 out of 14 liars).

\section{Mentioning people}

Table 3 finally shows that a similar number of truth tellers $(n=11)$ and liars $(n$ $=10)$ reported that they mentioned people in their statements, $\chi^{2}(1, \mathrm{n}=50)=.01, p=$ 
$.92, p h i=.02$. The reason why they did so differed between truth tellers and liars,

$\chi^{2}(4, \mathrm{n}=21)=11.93, p=.018, p h i=.75$. Truth tellers mentioned other people so that they could back up their statement (5 out of 11 truth tellers) and because they were involved in the incident (4 out of 11 truth tellers). Liars did so because it would make the story sound more believable (3 out of 10 liars). Liars also reported that they avoided mentioning specifics about these people so that they could not be contacted (5 out of 10 liars).

\section{Discussion}

Truth tellers included more verifiable details in their statement than liars (supporting Hypothesis 1), whereas liars included more unverifiable details in their statement than truth tellers. A total of $84 \%$ of truth tellers and $44 \%$ of liars included more verifiable than unverifiable detail into their accounts. Therefore, when the decision rule 'Those who include more verifiable than unverifiable details in their statements are truth tellers' was used $84 \%$ of truth tellers and $56 \%$ of liars $(70 \%$ in total) were correctly classified. Of course, we should be cautious with interpreting such a decision rule after a single study. Despite this, we believe that the percentage for truth tellers is encouraging and demonstrates the potential of the verifiability approach to classify truth tellers in insurance claim settings. The percentage for liars is relatively low but there is no real reason for concern. The liars who included verifiable details in their statements have been bluffing (for example claiming that CCTV footage would show the incident) and these liars may fall through if investigators will actually check the verifiable details they provided, something they may do in real life. Although we have no evidence to support it, we further think that the percentage of liars who make up verifiable detail may be higher in an experiment 
than in real life, because liars may find it more unlikely in experiments than in real life that investigators will actually check the details they provide. However, also in real life liars will report checkable detail, so the presence of checkable detail does not necessarily mean that the interviewee is truthful. In addition, perhaps truth tellers have more verifiable details to report if they have a strong memory of the incident. Their memory is more likely to be strong if an event happened recently. This could be examined in future research.

The finding that truth tellers included more verifiable detail in their statements than liars is different from Nahari, Leal et al. (2014), who found no difference between truth tellers and liars in reporting verifiable detail in their insurance claim experiment. The important difference between the present study and Nahari, Leal et al. (2014) was that in the present study participants were informed that they may be asked further questions to check the verifiability of their statement whereas no such instruction was given by Nahari, Leal et al. (2014). Previous research has shown that such an instruction enlarges the difference in reporting verifiable detail between truth tellers and liars (Nahari, Vrij, \& Fisher, 2014b), because it is easier for liars than for truth tellers to include such detail. We believe that such an instruction is easy to provide and far easier to provide than many other techniques that are used to distinguish truth tellers from liars (e.g., polygraph tests [Kleiner, 2002], behavior analysis interview, Horvath, Blair, \& Buckley, 2002). Of course, conclusive evidence whether the differences in results between Nahari et al. (2014b) and the present study is caused by the instruction that the verifiability of their statement may be checked can only be given if instruction is experimentally manipulated. It is worthwhile to pursue such an experiment. 
The verifiability approach in insurance settings

Both truth tellers and liars mentioned frequently that they were with friends when the incident happened but they interacted with these friends in different ways: Truth tellers were more likely than liars to discuss the incident with these friends. When noticing a loss or theft on an evening out with friends it seems logical to discuss it with these friends, but it would complicate things for liars (as they then need to lie to friends about this loss or theft) and liars may therefore be less likely to do that. In addition, truth tellers were more likely to mention CCTV footage than liars. Again, liars make their lies complicated if they start referring to CCTV footage, as that footage could make clear that they are lying. In other words, there are good reasons why liars were reluctant to mention friends and CCTV footage and that reluctance gave their lies away.

Interestingly, no difference emerged between truth tellers and liars in reporting the incident to officials, such as police or bar tenders. An explanation as to why no difference emerged in reporting the incident to the police is that only $36 \%$ of truth tellers reported to have done that. This percentage does not deviate much from the official percentage of recorded offences to the police in the UK in 2013 (49\%, Office for National Statistics, 2013).

Regarding other officials, relatively many liars (44\%) claimed to have spoken to such persons. A possible explanation as to why so many liars reported to have done this is that they may think that the chances are small that this information can actually be checked. Indeed, if a bar tender says that no-one asked him last week about a missing phone, the liar can argue reasonably convincingly that the bar tender may have forgotten it. 
The verifiability approach in insurance settings

In terms of correctly classifying truth tellers and liars, $88 \%$ of truth tellers and $64 \%$ of liars mentioned at least one witness factor (Total witness factor). Thus if the decision rule 'those who include a witness factor in their statement are telling the truth' $88 \%$ of truth tellers and $36 \%$ of liars would be correctly classified, resulting in a $62 \%$ accuracy rate. This accuracy rate is similar to the $66 \%$ accuracy rate reported by Nahari, Leal, et al. (2014). The percentage for liars in particular is low but, as we mentioned above, this results from liars bluffing and making false witness claims, something they may be less likely to do in real life.

None of the individual witness factors (friends, police, other officials, CCTV footage) revealed classification rates high enough to recommend investigators to rely upon such factors in real life. The problem is mainly caused by truth tellers. Although the number of liars who falsely mention these factors is relatively low (perhaps with the exception of mentioning other officials), truth tellers do not mention such factors very often either. This is in all likelihood caused by the nature of the incident. For example, one truth teller reported that she had left her window open while she was not in her room and that during that time her laptop was stolen. Indeed, it is difficult to see which verifiable details she could have included in her statement. Our data support the notion that the nature of the incident is important. When we specified a situation suitable to examine the 'friends informed' factor (e.g., an incident that happened in a public location while being out with friends), the percentages for truth tellers became higher. That is, $77 \%$ of truth tellers who lost something in a public location while being out with friends, informed these friends about the loss. For liars this was only $17 \%$. Thus the decision rule 'When reporting a loss or theft in a public location while being out with friends, those who mention this loss or theft to their friends are truth tellers' $77 \%$ of truth tellers and $83 \%$ of liars ( $80 \%$ in total) were 
classified correctly. It is clear that the verifiable detail approach may work better in some insurance claim settings than in others. It seems to work well when people describe incidents that occurred when they were out with friends, but it probably works less well if something happened at home when they were not there, and perhaps in other situations. Detailing which insurance situations are suitable and which are not suitable for the verifiable detail approach is worth pursuing in future research.

Although truth tellers rated their own statements more convincing than liars, there was no difference between truth tellers and liars in the extent to which they thought their statement was verifiable and how difficult they found it to include verifiable detail in their statements. The findings for the statement being verifiable are interesting as truthful statements were actually more verifiable than deceptive statements. This means that either truth tellers underestimated how verifiable their statements were or liars overestimated this. The mean scores were rather high $(65 \%$ on a $100 \%$ scale) indicating that both truth tellers and liars thought that their statements were largely verifiable. This suggests that liars were inclined to overestimate how verifiable their statements were. This is an interesting finding. If liars are informed that insurance claim investigators look for verifiable detail liars may try to include such detail in their statement. Given the difficulty of doing this they are likely to opt for a minimum approach and to add just enough verifiable details to satisfy the investigator. If they overestimate the number of verifiable detail they include, they actually may fall short when they think they have complied with the request. 
Truth tellers and liars found the task to include verifiable details equally difficult and the open-ended questions revealed what made the task difficult for them: Both groups said that there were sometimes no verifiable details to report (this was mentioned by 8 out of 25 truth tellers). This finding demonstrates the limitation of using the verifiable approach in insurance claim settings, as the approach can only work if truth tellers can provide verifiable details. As we mentioned above, that is difficult in some insurance settings. It may also be difficult when the event happened a long time ago as the interviewee may then have forgotten such details. The openended questions also revealed strategies used by truth tellers and liars. Truth tellers mentioned reporting small details whereas liars also mentioned this with the addition that they avoided providing specific details. Moreover, truth tellers mentioned that they added details about times, locations and people so that their statement could be checked and became more accurate and clearer, liars mentioned that they did this so that the statement sounded more believable. Again, liars reported that they avoided mentioning specific detail. Future research could examine what liars exactly mean with 'specific detail' because, if liars avoid these, it could potentially discriminate truth tellers from liars in insurance claim settings.

Four methodological issues merit attention. First, in this study truth tellers had experienced loss, damage or theft, whereas liars did not. This means that truth tellers and liars did not only differ in terms of veracity status but also in terms of having experienced loss, damage or theft. We do not think that this is problematic. It often happens that liars include detail that they have not actually experienced (Köhnken, 2004; Leins, Fisher, \& Ross, 2013; Vrij, 2008), so our experiment reflects real life. In addition, it is common in deception research that liars are instructed to report something they have not experienced; and, subsequently, they are often given details 
about what to report (Vrij, 2008). In the present experiment, we did not give liars such an instruction and gave them the freedom to fabricate their own story. Since liars prefer to embed their lies in truthful stories (Hogue, Levashina, \& Hang, 2013; Leins et al., 2013; Vrij, 2008), we therefore can assume that many liars did this and described a truthful experience (e.g., a night out with friends), but embedded a lie in that story (e.g., theft of a phone). The finding that liars indicated that on average $15 \%$ of their story was truthful suggests that they used such a strategy, so does the finding that they reported that a 'vague memory' hampered them to report details. This freedom for liars to come up with their own story may also explain why in the present experiment the total number of detail given by truth tellers and liars did not differ between truth tellers and liars, whereas in deception research it typically does.

Second, one might argue that truth tellers' experience with loss, theft or damage could have made them aware that insurance companies might look for verifiable detail. If so, truth tellers more than liars may have been geared up for providing such detail. We do not think that this has happened. We explicitly asked participants to include, if possible, verifiable detail in their statements. In other words, liars were explicitly reminded of the task in hand.

Third, most truth tellers will probably have discussed their loss, damage or theft with at least one other person. In that respect they have 'rehearsed' their story. Liars, obviously, will not have discussed their story with other people, but that does not mean that their story was not rehearsed, as we gave them time to prepare their story before writing it down.

Fourth, our participants were relatively young and their stories reflected their age (many stories were about losing a phone on a night out in a pub or nightclub). We 
The verifiability approach in insurance settings

cannot rule out that older people will tell different stories, which include different types of verifiable detail than this 'night out' scenario. Future research could examine this. Importantly, from a theoretical perspective the principle tested in this paper 'truth tellers include more verifiable details than liars' should work for all age groups.

In conclusion, the experiment demonstrated that the verifiability approach can be used in insurance claim settings to distinguish truth tellers from liars with truth tellers providing more verifiable detail than liars. However, when applying the approach to an insurance setting, one should be aware that the approach probably works better in some insurance claim settings than in others, as sometimes even truth tellers will not be able to report verifiable details. 


\section{References}

Bell, B. E., \& Loftus, E. F. (1989). Trivial persuasion in the courtroom: The power of (a few) minor details. Journal of Personality and Social Psychology, 56, 669-679.

DOI: $10.1037 / / 0022-3514.56 .5 .669$

Brandon, S. (2011). Impacts of psychological science on national security agencies post 9/11. American Psychologist, 66, 495-506.

Colwell, K., Hiscock-Anisman, C., Memon, A., Woods, D., \& Michlik, P. M. (2006). Strategies of impression management among deceivers and truth tellers: How liars attempt to convince. Amercian Journal of Forensic Psychology, 24, 31-38.

DePaulo, B. M., Ansfield, M. E., Kirkendol, S. E., \& Boden, J. M. (2004). Serious lies. Basic and Applied Social Psychology, 26, 147-167.

DePaulo, B. M., \& Bell, K. L. (1996). Truth and investment: Lies are told to those who care. Journal of Personality and Social Psychology, 70, 703-716.

DePaulo, B. M., \& Kashy, D. A. (1998). Everyday lies in close and casual relationships. Journal of Personality and Social Psychology, 74, 63-79.

DePaulo, B. M., Lindsay, J. L., Malone, B. E., Muhlenbruck, L., Charlton, K., \& Cooper, H. (2003). Cues to deception. Psychological Bulletin, 129, 74-118. DOI: $10.1037 / 0033-2909.129 .1 .74$

Elaad, E. (2003). Effects of feedback on the overestimated capacity to detect lies and the underestimated ability to tell lies. Applied Cognitive Psychology, 17, 349-363.

Hartwig, M., Granhag, P. A., \& Strömwall, L. (2007). Guilty and innocent suspects' strategies during police interrogations. Psychology, Crime, \& Law, 13, 213-227. 
DOI: $10.1080 / 10683160600750264$

Hartwig, M., Granhag, P. A., Strömwall, L, \& Doering, N. (2010). Impression and information management: On the strategic self-regulation of innocent and guilty suspects. The Open Criminology Journal, 3, 10-16 (special issue on deception research).

Hogue, M., Levashina, J., \& Hang, H. (2013). Will I fake it? The interplay of gender, Machiavellianism, and self-monitoring on strategies for honesty in job interviews. Journal of Business Ethics, 117, 399-411. DOI: 10.1007/s10551012-1525-x.

Horvath, F., Blair, J. P., \& Buckley, J. P. (2008). The Behavioral Analysis Interview: Clarifying the practice, theory and understanding of its use and effectiveness. International Journal of Police Science and Management, 10, 101-118.

Johnson, M. K. (2006). Memory and reality. American Psychologist, 61, 760-771. doi: $\underline{10.1037 / 0003-066 X .61 .8 .760}$

Johnson, M. K., Foley, M. A., Suengas, A. G., \& Raye, C. L. (1988).Phenomenal characteristics of memories for perceived and imagined autobiographical events. Journal of Experimental Psychology: General, 117, 371-376. doi: 10.1037/0096-3445.117.4.371

Kleiner, M. (2002). Handbook of polygraph testing. San Diego, CA: Academic Press.

Köhnken, G. (2004). Statement Validity Analysis and the 'detection of the truth'. In P. A. Granhag \& L. A. Strömwall (Eds.), Deception detection in forensic contexts (pp. 41-63). Cambridge, England: Cambridge University Press.

Leal, S., Vrij, A., Warmelink, L., Vernham, Z., \& Fisher, R. (2015). You can’t hide your telephone lies: Providing a model statement as an aid to detect deception 
The verifiability approach in insurance settings

in insurance telephone calls. Legal and Criminological Psychology, 20, 129146. DOI: $10.1111 /$ lcrp. 12017

Leins, D., Fisher, R. P., \& Ross, S. J. (2013). Exploring liars'strategies for creating deceptive reports. Legal and Criminological Psychology, 18, 141-151. DOI: 10.1111/j.2044-8333.2011.02041.x

Masip, J., Sporer, S., Garrido, E., \& Herrero, C. (2005). The detection of deception with the reality monitoring approach: A review of the empirical evidence. Psychology, Crime, \& Law, 11, 99-122.

Masip, J., \&Herrero, C. (2013). 'What would you say if you were guilty? Suspects' strategies during a hypothetical behavior analysis interview concerning a Serious Crime. Applied Cognitive Psychology, 27, 60-70.doi:

10.1002/acp. 2872

Nahari, G., Leal, S., Vrij, A., Warmelink, L., \& Vernham, Z. (2014). Did somebody see it? Applying the verifiability approach to insurance claims interviews. Journal of Investigative Psychology and Offender Profiling, 11, 237-243. DOI: $10.1002 /$ jip.1417.

Nahari, G., \& Vrij, A. (2014). Can I borrow your alibi? The applicability of the verifiability approach to the case of an alibi witness. Journal of Applied Research in Memory and Cognition, 3, 89-94.

DOI.ORG/10.1016/J/JARMAC.2014.04.005

Nahari, G., Vrij, A., \& Fisher, R. (2014a). Exploiting liars' verbal strategies by examining unverifiable details. Legal and Criminological Psychology, 19, 227-239, DOI:10.1111/j.2044-8333.2012.02069.x 
Nahari, G., Vrij, A., \& Fisher, R. (2014b). The verifiability approach: countermeasures facilitate its ability to discriminate between truths and lies. Applied Cognitive Psychology, 28, 122 - 128. DOI: 10.1002/acp.2974

Nahari, G., Vrij, A., \& Fisher, R. P. (2012). Does the truth come out in the writing? Scan as a lie detection tool. Law and Human Behavior, 36, 68-76. doi: $10.1037 / \mathrm{h} 0093965$

Office for National Statistics (2013). Crime in England and Wales, Year Ending December 2013 (http://www.ons.gov.uk/ons/dcp171778_360216.pdf).

Olson, E. A., \& Wells, G. L. (2004). What makes a good alibi? A proposed taxonomy.Law and Human Behavior, 28, 157 176.doi:10.1023/B:LAHU.0000022320.47112.d3

Payne, H. J. (2007). Targets, strategies, and topics of deception among part-time workers. Employee Relations, 30, 251-263. DOI 10.1108/01425450810866523.

Vrij, A. (2008). Detecting lies and deceit: Pitfalls and opportunities: Chichester: John Wiley and Sons.

Vrij, A., \& Granhag, P. A. (2012). Eliciting cues to deception and truth: What matters are the questions asked. Journal of Applied Research in Memory and Cognition, 1, 110-117. doi.org/10.1016/j.jarmac.2012.02.004

Vrij, A., \& Granhag, P. A. (2014). Eliciting information and detecting lies in intelligence interviewing: An overview of recent research. Applied Cognitive Psychology, 28, 936-944. DOI: 10.1002/acp.3071.

Vrij, A., Mann, S., Leal, S., \& Granhag, P. A. (2010). Getting into the minds of pairs of liars and truth tellers: An examination of their strategies. The Open Criminology Journal, 3, 17-22. DOI: 10.2174/1874917801003010017 
The verifiability approach in insurance settings 
The verifiability approach in insurance settings

Table 1. Questionnaire data as a Function of Veracity

\begin{tabular}{lcccccccc}
\hline & \multicolumn{2}{c}{ Truth } & \multicolumn{2}{c}{ Lie } & & & \\
\cline { 2 - 8 } & M & SD & M & SD & $t$ & $p$ & $\boldsymbol{d}$ \\
\cline { 2 - 8 } How much of your statement & 96.00 & 12.24 & 14.80 & 26.94 & $13.72^{1}$ & .000 & 4.14 \\
was truthful? & & & & & & & \\
Motivation & 87.20 & 13.08 & 82.40 & 24.03 & .88 & .385 & .26 \\
Were you convincing? & 80.40 & 22.26 & 64.40 & 22.74 & 2.51 & .015 & .71 \\
Was statement verifiable? & 73.20 & 29.26 & 61.20 & 29.06 & 1.46 & .152 & .27 \\
How difficult was it to & 50.40 & 32.97 & 52.00 & 28.28 & .18 & .855 & .05 \\
include verifiable detail? & & & & & & &
\end{tabular}

${ }^{1}$ Variances of groups (truth, lie) were unequal and t-test was calculated accordingly 
The verifiability approach in insurance settings

Table 2. Analyses of Statements as a Function of Veracity

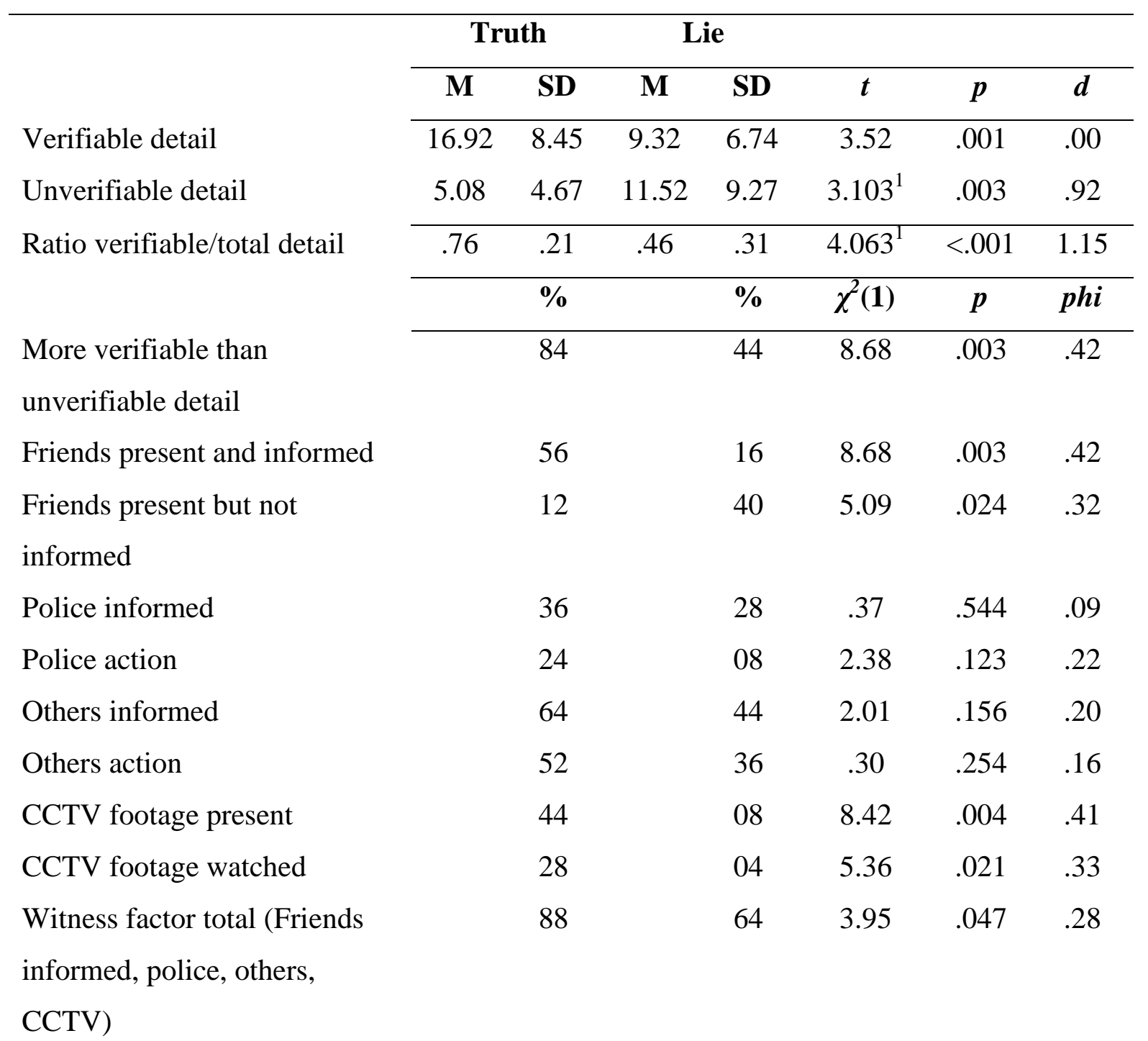

${ }^{1}$ Variances of groups (truth, lie) were unequal and t-test was calculated accordingly 
Table 3. Analyses of Open-ended Questions as a Function of Veracity

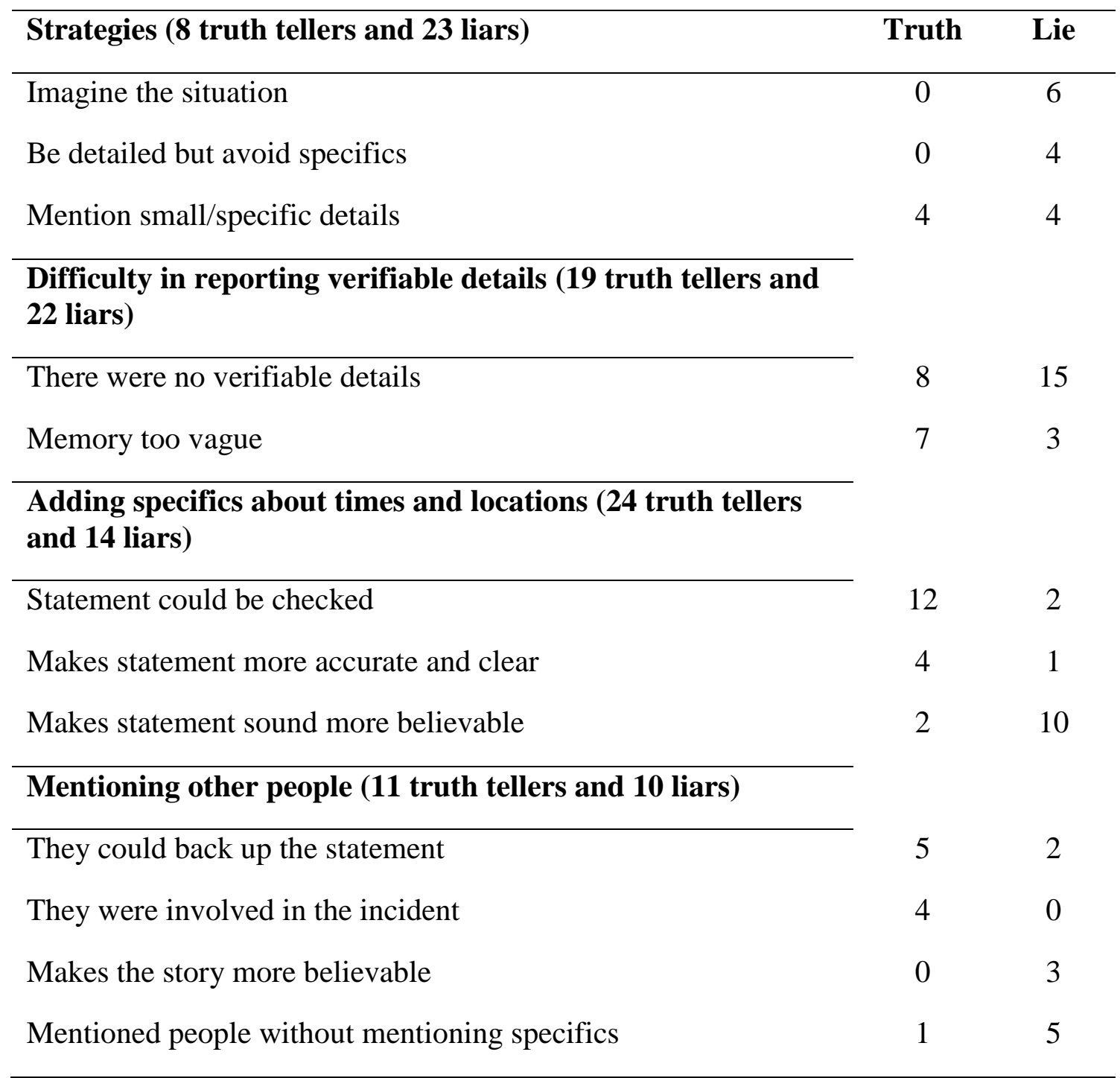

